\title{
The PrEP You Want: A Web-Based Survey of Online Cross-Border Shopping for HIV Prophylaxis Medications
}

Ben Walmsley ${ }^{1}$, BA; Dan Gallant ${ }^{2}$, BA, MA; Mark Naccarato ${ }^{1}$, BPharm; Mark Hull ${ }^{3}$, BSc, MSc, MD; Alex Smith ${ }^{4}$, BSN; Darrell Hoi-San Tan ${ }^{1}$, BSc, MD, PhD

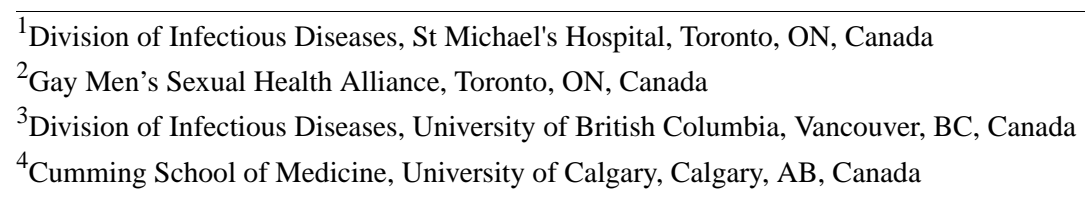

Corresponding Author:

Ben Walmsley, BA

Division of Infectious Diseases

St Michael's Hospital

209 Victoria Street

Toronto, ON, M5B 1T8

Canada

Phone: 14168646060 ext 77105

Email: ben.j.walmsley@gmail.com

\section{Abstract}

Background: In response to the high cost of HIV pre-exposure prophylaxis (PrEP) medications in Canada, community organizations have created internet-based guides detailing how to legally order generic medications online and travel to collect them in the United States. However, little is known about the patients following these guides.

Objective: Our primary objective was to measure the proportion of Ontario gay, bisexual, and other men who have sex with men (GBMSM) accessing these online guides who intended to use the border-crossing approach. Our secondary objectives were to explore their demographic characteristics, their completion of the steps in the border-crossing approach, and the barriers they perceived.

Methods: Between July 20, 2017, and May 18, 2018, we administered two online surveys of GBMSM accessing an online border-crossing guide posted by a gay men's health organization in Ontario. Participants completed an open baseline survey posted on the border-crossing guide's Web page and a follow-up survey 3 months later. The data were analyzed using descriptive statistics. We used multivariable logistic regression to identify characteristics associated with the intention to use the border-crossing approach.

Results: Most of the 141 participants were young (median age 23, interquartile range 22-25 years) and black (79.4\%; 112/141) GBMSM who had completed a college or an undergraduate degree $(62.4 \%$; 88/141). In addition, 19.9\% (28/141) of them reported a total family income less than Can $\$ 30,000$ and another 53.9\% (76/141) reported income between Can $\$ 30,000$ and Can $\$ 60,000$. $54.6 \%(76 / 141)$ paid for medications entirely out of pocket. Most participants indicated that they were likely to complete a border-crossing approach: $80.1 \%(113 / 141)$ at baseline and $79.1 \%(87 / 110)$ at follow-up. The characteristics associated with the intention to use the approach included being black (adjusted odds ratio [aOR] 5.73, 95\% CI 2.06-16.61), paying for medications out of pocket (aOR 5.18, 95\% CI 1.82-17.04), and having a provider who was thought to be willing to prescribe PrEP (aOR 4.42, 95\% CI 1.63-12.41). Comparing baseline and follow-up for the 110 participants who completed both surveys, 65.4\% (72/110) and $80.0 \%(88 / 110)$ had discussed PrEP with a health care provider, 18.1\% (20/110) and 25.4\% (28/110) had obtained a PrEP prescription, and $8.2 \%(9 / 110)$ and 5.5\% (6/110) had ordered medications to that mailbox, whereas only $1.0 \%(1 / 110)$ and $0.0 \%$ $(0 / 110)$ had crossed the border to collect them at baseline and follow-up, respectively. Reported barriers included perceived concerns about the approach's legality $(56.0 \% ; 79 / 141)$, the security of personal health information $(39.0 \% ; 55 / 141)$, and the safety of online vendors $(38.3 \% ; 54 / 141)$.

Conclusions: Despite high interest in pursuing an online border-crossing approach to get PrEP medications, such an approach may not be a viable option for PrEP scale-up among interested GBMSM because of logistical challenges and perceptions of safety and legitimacy. 
(J Med Internet Res 2019;21(7):e12076) doi: 10.2196/12076

\section{KEYWORDS}

pre-exposure prophylaxis; tenofovir disoproxil fumarate/emtricitabine; generic antiretroviral drugs; online medication shopping; men who have sex with men; HIV

\section{Introduction}

\section{Background}

HIV infection rates remain high among gay, bisexual, and other men who have sex with men (GBMSM) living in Canada, accounting for an estimated $47.9 \%$ of the nation's 2328 new adult cases in 2016 [1]. Pre-exposure prophylaxis (PrEP) is a promising strategy for preventing HIV infection [2]. Pharmacokinetic models suggest that consistent use of PrEP, which currently involves regular oral dosing of two coformulated antiretroviral medications, tenofovir disoproxil fumarate and emtricitabine (TDF/FTC), reduces the risk of HIV infection by almost $100 \%$ in GBMSM [3-5]. Furthermore, we have documented high and increasing willingness to use PrEP among GBMSM living in Canada. Although 33.3\% of a sample of GBMSM attending a major Toronto sexual health clinic for HIV testing in 2011 said they would definitely be willing to use PrEP, this proportion increased to $52.5 \%$ in 2015 [6].

Despite this interest, the cost of PrEP medications has been a barrier to its uptake in Canada, where health services are publicly funded but medication costs are not universally covered. Brand name TDF/FTC (Truvada) costs approximately Can $\$ 876$ per month in Ontario [7], and although generic TDF/FTC is less expensive at approximately Can $\$ 220$ per month, this cost remains excessive for many. PrEP is publicly subsidized in some but not all Canadian jurisdictions at present, and in some cases, including Ontario, coverage may be only partial, requiring out-of-pocket copayments. Accordingly, the cost of PrEP is still prohibitive for many Canadians [8]. PrEP access in other high-income jurisdictions is variable, although notable examples of truly universal PrEP coverage have begun to emerge, including in France, Scotland, and New South Wales.

In response to this barrier in Canada, motivated patients have been pursuing alternate strategies to obtain less expensive generic PrEP medication, including crossing the border to the United States to pick up PrEP that they have ordered online [9]. Although having prescription drugs shipped directly into Canada for personal use is illegal [10], individuals crossing the border can legally import up to 90 days' worth of medication for personal use. Therefore, innovative activists and community organizations have created online resources detailing how a border-crossing approach can be used to legally acquire more affordable PrEP. The process involves four basic steps: (1) getting a prescription, (2) getting a mailbox in a US border location, (3) ordering medication online that ships to that location, and (4) picking up medication from that US location and crossing the border back to Canada every 3 months as needed. This approach is legal and, thus, its safety should be similar to crossing the border for any other reason. Reports from community members and clinicians alike indicate that this approach has been widely used in British Columbia [9,11], and a new campaign began promoting the strategy in Ontario in mid-2017. However, there are few data on the characteristics and motivations of the strategy's users in any setting and any perceived or actual barriers they may face.

\section{Objectives}

To address these gaps, we conducted two Web-based surveys, one baseline and one follow-up, of GBMSM who were considering following the border-crossing approach as described by the major Ontario community organization championing the new campaign, the Gay Men's Sexual Health Alliance (GMSH), in an online resource titled The PrEP You Want [12]. Our primary objective was to measure the proportion of individuals accessing the resource who indicated an intention to use the border-crossing approach. Our secondary objectives were to explore their characteristics, their completion of the steps in the border-crossing process (Textbox 1), and the barriers they perceived.

Textbox 1. Steps in a cascade of online shopping and border crossing to obtain pre-exposure prophylaxis (PrEP).

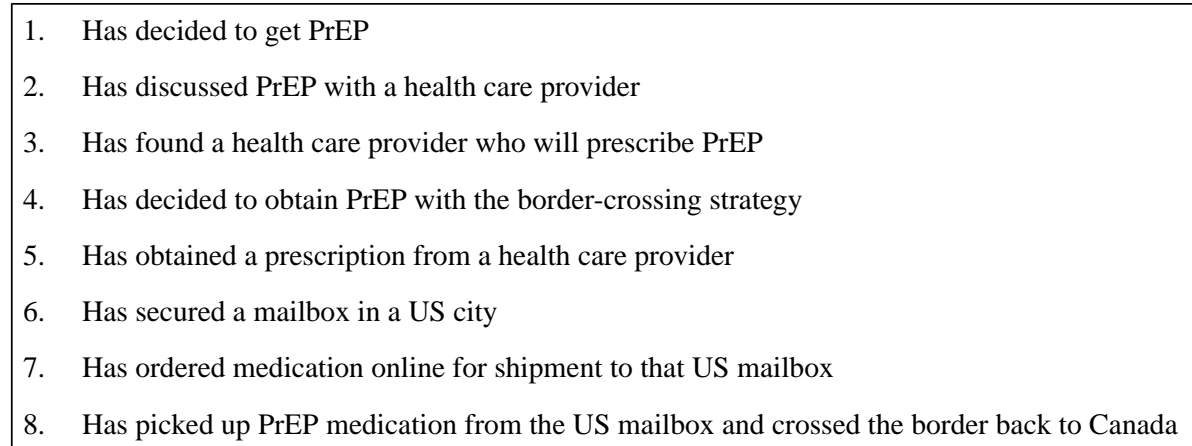




\section{Methods}

\section{Study Design}

Between July 20, 2017, and May 18, 2018, we administered two online surveys, one baseline and one follow-up, of GBMSM considering the border-crossing approach. The study was an open survey: to enter the study, anyone who self-reported that they met the eligibility criteria could access it by clicking on an online study link. We posted the link on the GMSH online information page, and the GMSH advertised this information page on several websites (eg, AIDS Committee of Toronto website, PrEP_Canada: Rethinking HIV Prevention Facebook page). We sent all the eligible participants a baseline questionnaire along with a unique participant study code by email, and after 3 months, we sent a follow-up questionnaire to capture updated information on their experience. For both the baseline and the follow-up surveys, we contacted participants who had not yet completed their questionnaires two more times with reminders.

\section{Participants}

The participants were eligible if they self-identified as being gay, bisexual, or otherwise a man who has sex with men; were residents of Ontario; were first-time participants in the study; and were able to read and write English. In addition, they had to report having read the GMSH online information page and having determined whether they were likely to use the strategy or not. All participants were offered a Can $\$ 5$ electronic gift card on completion of the baseline questionnaire, and a Can $\$ 10$ electronic gift card on completion of the follow-up questionnaire.

\section{Survey Instrument}

We designed both the 37-item baseline questionnaire and the 27-item follow-up questionnaire based on previous surveys of potential PrEP users [13] and the language of the GMSH online resource. The questionnaires covered the following domains: demographics; HIV risk behaviors; health care access; knowledge and experience of PrEP; and interest and experience with the border-crossing strategy. We developed the demographic section to match a standardized health equity questionnaire developed by major health care organizations in Toronto [14]. The HIV risk section included all items from the High Incidence Risk Index for men who have sex with men (HIRI-MSM), a HIV risk index developed and validated by the US Centers for Disease Control for its use in predicting seroconversion in GBMSM [15]. It should be noted that although the HIRI-MSM questions are based on 6-month look-back intervals, our questionnaires used 3-month intervals to avoid overlap between the baseline and follow-up responses; these 3-month responses were then doubled to estimate the final HIRI-MSM scores. We housed both surveys on the website HostedinCanadaSurveys.

\section{Analysis}

Data were primarily analyzed with descriptive statistics, and the analysis was conducted separately for the baseline data and the follow-up data. For the primary objective, we calculated the proportion of individuals who answered likely or very likely to the question: "How likely is it that you will use this 'The PrEP You Want: How to Order PrEP Online' approach to buy generic PrEP drugs?". For the secondary objectives, we calculated the proportion of individuals who reported completing each of the cascade of steps in Textbox 1 and the proportion reporting a variety of barriers to carrying out The PrEP You Want approach.

As an exploratory analysis, we constructed univariable and multivariable logistic regression models quantifying the relationship between respondent characteristics and interest in using the border-crossing approach, first using the baseline data only and subsequently using the follow-up data. When building the multivariable models, we first excluded variables that were highly correlated and then included variables in the final model if they modified the beta estimate for the primary predictor variable of interest, medication insurance status, by more than $10 \%$. To investigate the possibility of falsified responses, we conducted a sensitivity analysis comparing the demographic characteristics and primary outcome responses among the decile of respondents with the shortest survey completion times with those of the total sample. In addition, we conducted a log file analysis to confirm that responses corresponded with unique internet protocol addresses. All quantitative analysis was done using R software (R Core Team).

\section{Sample Size Considerations}

The sample size for this study was based on the minimum required sample size to ascertain, among individuals accessing the website, the proportion indicating an intention to use the border-crossing strategy with reasonable precision. There were no previous data to our knowledge on the likely value of this proportion, so we conservatively assumed that the true proportion was 0.5 (the value that generates the largest potential sample size requirements). We determined that a target sample size of 150 respondents for the baseline questionnaire would allow us to estimate the true prevalence with reasonable precision (plus or minus 8\%) [16].

\section{Ethical Approval}

This study was approved by the University of Toronto's HIV Research Ethics Board and the St Michael's Hospital Research Ethics Board before any study activities were initiated. All the participants documented their consent online before beginning either of the surveys.

\section{Results}

\section{Survey Response}

All 163 individuals who provided a valid email address were sent the baseline survey. Of the 158 participants who then began the baseline survey, 17 were excluded because of incomplete responses $(n=5)$, repeat responses $(n=6)$, and being non-Ontarian $(n=6)$. Of the 141 participants included in the final baseline analysis, 110 provided complete responses to the follow-up survey and were included in the final follow-up analysis. The number of unique site visitors (ie, participants exposed to the survey link) could not be calculated as the survey link was likely shared through multiple informal channels. 


\section{Demographics}

Participant characteristics are described in Table 1. Median age was 23 (interquartile range [IQR] 22-25) years at baseline, and none of the respondents were below 18 years old. Most of the baseline participants were black $(79.4 \%$; 112/141), gay $(87.2 \%$; $123 / 141)$, and male $(98.6 \% ; 139 / 141)$, and $62.4 \%$ (88/141) had a college or undergraduate education or higher. Less than half $(45.4 \%$; 64/141) had drug coverage but most $(83.0 \%$; 117/141) had a family doctor or nurse practitioner with whom they felt comfortable discussing their sexual health. An HIRI-MSM score could be calculated for the 139 participants who answered all the requisite questions. The median HIRI-MSM score was 29 (IQR 26-30), and 97.8\% (136/139) of men scored more than or equal to 10 , meeting the index's criteria for high HIV risk. Characteristics of the 110 participants who completed the follow-up survey and the 31 who were lost to follow-up were similar (data not shown). None of the demographic or behavioral variables were significantly associated with completion of the follow-up survey. 
Table 1. Participant characteristics.

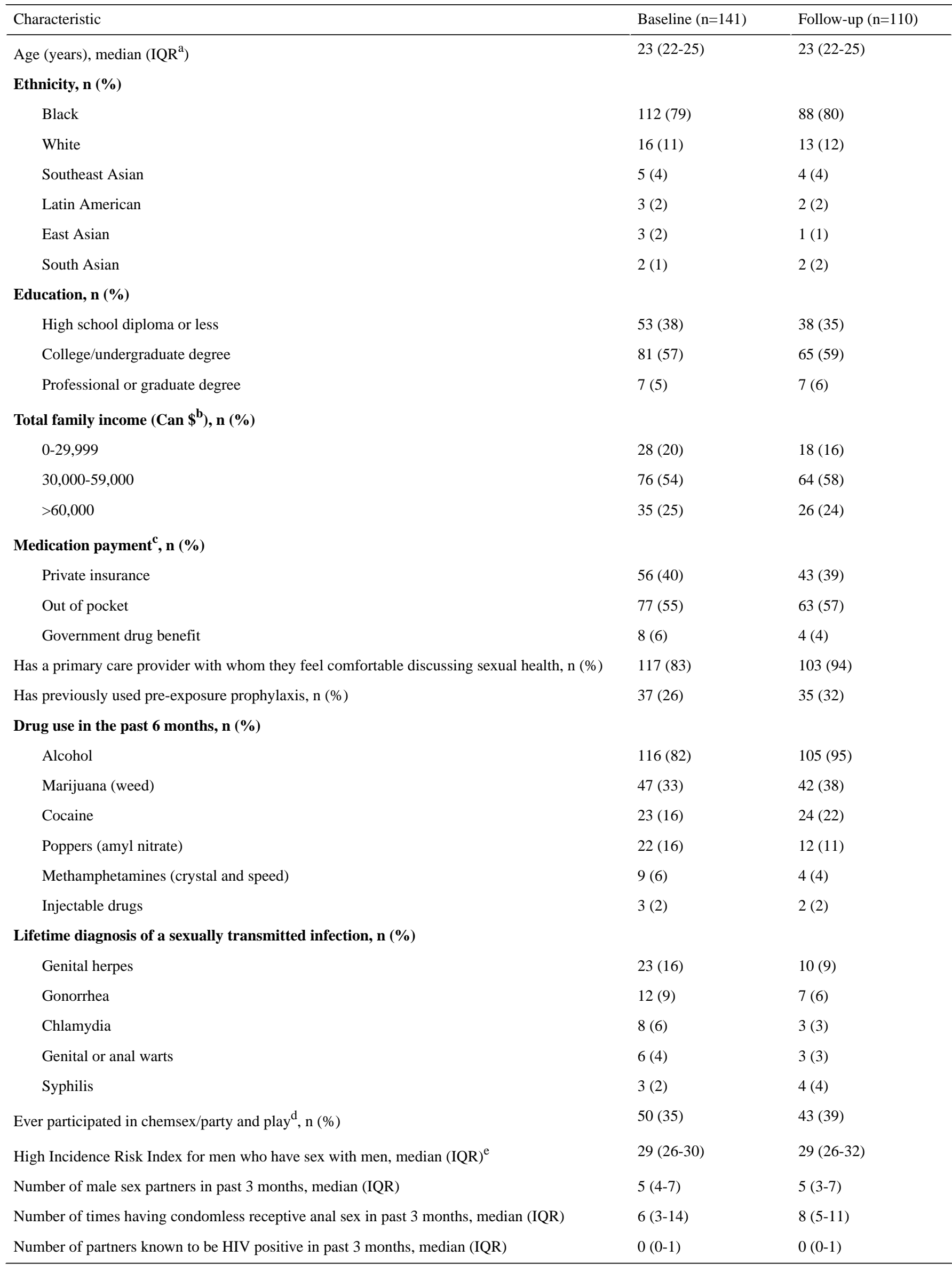

${ }^{\mathrm{a}} \mathrm{IQR}$ : interquartile range. 
b Two participants responded Don't know in both baseline and follow-up.

${ }^{\mathrm{c}}$ Two participants did not respond in the baseline.

${ }^{\mathrm{d}}$ One participant did not respond in the baseline.

${ }^{\mathrm{e}}$ Two participants did not answer all of the requisite risk questions in the baseline survey.

\section{Primary Outcomes}

In the primary analysis, $80.1 \%$ of participants indicated that they were likely to use the border-crossing approach. This proportion was similar at follow-up $(79.1 \% ; 87 / 110)$. More than half of the participants had first heard about the approach from a friend $(55.3 \%$; 78/141), but participant responses varied by ethnicity: the leading response among black participants was from a friend $(66.1 \%$; 74/112), compared with only $20.6 \%$; $6 / 29$ ) of nonblack respondents, and the leading response among nonblack participants was media or online $(48.5 \%, 14 / 29)$.

At baseline, more than half of the participants had both decided that they wanted PrEP $(67.4 \%, 95 / 141)$ and already discussed PrEP with a health care provider $(62.4 \%, 88 / 141)$. However, only $46.1 \%(65 / 141)$ had found a health care provider who would be willing to prescribe PrEP and only $24.1 \%$ (34/141) had already obtained a prescription. Few participants had completed the steps of the cascade specific to border crossing such as obtaining a mailbox in the United States (Figure 1). At the 3-month follow-up, the 110 participants who had completed both surveys showed increased completion of preliminary steps but decreased completion of the final steps related to border crossing (Figure 1). Notably, only 10\% (11/110) of follow-up respondents had decided to obtain PrEP with a different method such as purchasing from a Canadian pharmacy.

We explored the variables associated with our primary outcome (likelihood of using the border-crossing approach) in exploratory logistic regression analyses separately for the baseline and follow-up data (Table 2). At baseline, factors associated with likeliness to use the border-crossing approach in both univariable and multivariable models included being black (adjusted odds ratio [aOR] 5.73, 95\% CI 2.06-16.61), paying for medications out of pocket (aOR $5.18,95 \%$ CI $1.82-17.04$ ), and having a provider who was thought to be willing to prescribe PrEP (aOR 4.42, 95\% CI 1.63-12.41). At follow-up, the findings were generally similar, as shown in Table 2. Only 9 individuals changed from being likely to unlikely to use the border-crossing approach between baseline and follow-up, whereas 8 did the reverse.

Figure 1. Steps completed in the border crossing for pre-exposure prophylaxis cascade at baseline and 3-months follow-up (n=110 participants who completed both surveys). PrEP: pre-exposure prophylaxis.

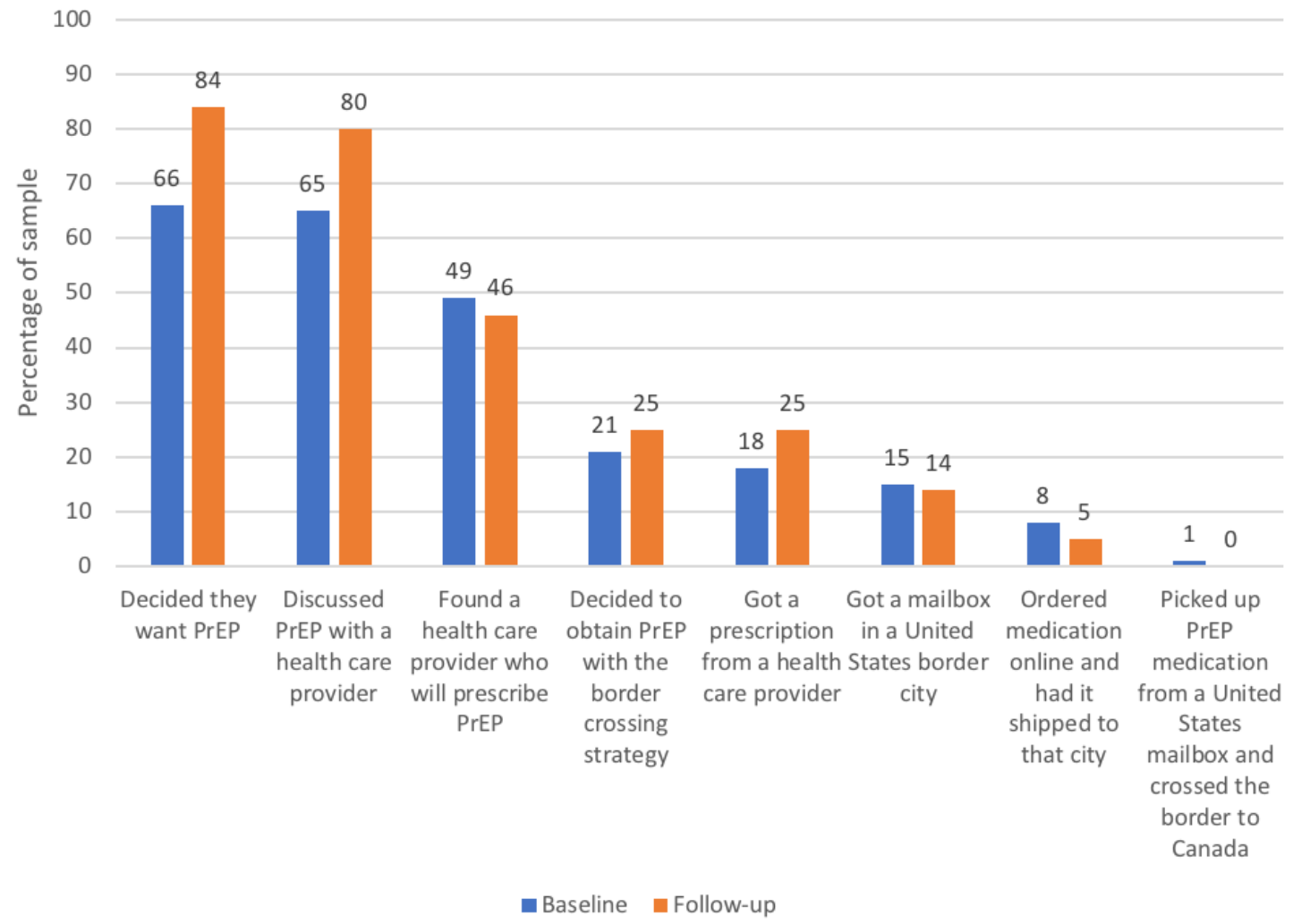


Table 2. Association between participant characteristics and the likelihood of using the border-crossing approach.

\begin{tabular}{|c|c|c|c|c|c|c|c|c|}
\hline \multirow[t]{3}{*}{ Participant characteristic } & \multicolumn{4}{|l|}{ Baseline } & \multicolumn{4}{|l|}{ Follow-up } \\
\hline & \multicolumn{2}{|l|}{ Univariable } & \multicolumn{2}{|l|}{ Multivariable } & \multicolumn{2}{|l|}{ Univariable } & \multicolumn{2}{|l|}{ Multivariable } \\
\hline & $\mathrm{OR}^{\mathrm{a}}(95 \% \mathrm{CI})$ & $P$ value & OR $(95 \% \mathrm{CI})$ & $P$ value & OR $(95 \% \mathrm{CI})$ & $P$ value & OR $(95 \% \mathrm{CI})$ & $P$ value \\
\hline \multicolumn{9}{|l|}{ Demographics } \\
\hline Age (years) & $0.74(0.61-0.87)$ & .001 & $-\mathrm{b}$ & - & $0.86(0.73-0.97)$ & .03 & - & - \\
\hline \multicolumn{9}{|l|}{ Ethnicity (ref: nonblack ${ }^{c}$ ) } \\
\hline Black & $8.20(3.30-21.19)$ & $<.001$ & $5.73(2.06-16.61)$ & .002 & 15.36 & $<.001$ & $\begin{array}{l}14.42(4.48- \\
53.11)\end{array}$ & $<.001$ \\
\hline \multicolumn{9}{|c|}{ Education (ref: high school diploma or less) } \\
\hline $\begin{array}{l}\text { College/undergradu- } \\
\text { ate degree or more }\end{array}$ & $0.49(0.18-1.19)$ & .10 & - & - & $0.79(0.28-2.07)$ & .64 & - & - \\
\hline \multicolumn{9}{|c|}{ Total family income (Can \$; ref: 0-29,999) } \\
\hline $30,000-59,000$ & $1.80(0.60-5.14)$ & .29 & - & - & $3.49(0.99-12.21)$ & .05 & - & - \\
\hline$>60,000$ & $0.76(0.24-2.31)$ & .62 & - & - & $0.69(0.19-2.34)$ & .69 & - & - \\
\hline
\end{tabular}

$\operatorname{PrEP}^{\mathbf{d}}$ access

Medication insurance (ref: private insurance or full government coverage)

$\begin{array}{llll}\text { Out of pocket } \quad 5.75(2.26-16.72) & <.001 \quad 5.18(1.82-17.04) \quad .003\end{array}$

Has a primary care $6.39(2.66-16.00) \quad<.001 \quad 4.42(1.63-12.41) \quad .004$ provider that the respon-

dent thinks would be

willing to prescribe PrEP

Has previously used

PrEP

Able and willing to pay more than Can $\$ 100$ per month for PrEP

\section{Risk factors} dex for men who have

sex with men score

Number of male sex

$1.05(0.90-1.23) \quad .63$

partners in the past 3

months

\section{Perceived chance of getting HIV in the next year (ref: little to none)}

More than a little or $0.97(0.37-2.87) \quad .9$

greater

Ever diagnosed with $1.94(0.72-6.18) \quad .19 \quad$ -

a sexually transmit-

ted infection

Party drug use in the $1.59(0.67-4.13) \quad .31$

past 6 months ${ }^{\mathrm{e}}$

Ever participated in

$2.34(0.93-6.76) \quad .12$

chemsex/party and play

\section{Perceptions of the border-crossing approach}

\section{First heard about the approach from (ref: friend[s])}

Other (health care

$0.25(0.10-0.60) \quad .003$

provider, community

organization, online,

etc)

$7.20(2.59-23.60) \quad<.001 \quad 6.69(2.07-\quad .003$

25.91)

$5.77(2.18-15.91)<.001 \quad-$

$3.88(1.21-17.37) \quad .04$

$1.02(0.37-3.10) \quad .97$

$1.10(1.04-1.18) \quad .002$

- $\quad 1.03(0.87-1.23) \quad .76$

$-\quad 0.53(0.20-1.42) \quad .19$

$-\quad 2.38(0.80-8.76) \quad .15$

$1.61(0.62-4.56) \quad .34$

.16

\begin{tabular}{l}
$-\quad 0.20(0.06-0.52) \quad .002$ \\
\hline
\end{tabular} 


\begin{tabular}{|c|c|c|c|c|c|c|c|c|}
\hline \multirow[t]{3}{*}{ Participant characteristic } & \multicolumn{4}{|l|}{ Baseline } & \multicolumn{4}{|l|}{ Follow-up } \\
\hline & Univariable & & Multivariable & & Univariable & & Multivariable & \\
\hline & $\mathrm{OR}^{\mathrm{a}}(95 \% \mathrm{CI})$ & $P$ value & OR $(95 \% \mathrm{CI})$ & $P$ value & OR $(95 \% \mathrm{CI})$ & $P$ value & OR $(95 \% \mathrm{CI})$ & $P$ value \\
\hline $\begin{array}{l}\text { Number of barriers } \\
\text { perceived/anticipat- } \\
\text { ed }\end{array}$ & $1.19(0.88-1.65)$ & .28 & - & - & $0.97(0.73-1.31)$ & .87 & - & - \\
\hline $\begin{array}{l}\text { Concerned about the } \\
\text { legality of the ap- } \\
\text { proach }\end{array}$ & $1.47(0.63-3.44)$ & .40 & - & - & $1.67(0.66-4.39)$ & .28 & - & - \\
\hline $\begin{array}{l}\text { Knows someone } \\
\text { who uses the ap- } \\
\text { proach }\end{array}$ & $6.70(2.53-21.20)$ & $<.001$ & - & - & $2.42(0.95-6.97)$ & .07 & - & - \\
\hline
\end{tabular}

a OR: odds ratio.

${ }^{\mathrm{b}}$ Further analysis not run on these variables.

${ }^{\mathrm{c}}$ White, East Asian, South Asian, and Latin American.

${ }^{\mathrm{d}}$ PrEP: pre-exposure prophylaxis.

e Party drugs specified as methamphetamines, gamma-hydroxybutyrate, amyl nitrate, cocaine, crack, ketamine, and injectable drugs.

\section{Motivators and Barriers}

The most commonly identified motivator to using the border-crossing approach was the high cost of PrEP at Canadian pharmacies $(59.6 \%, 84 / 141)$, with $57.4 \%$ (81/141)of the participants identifying a maximum monthly amount that they would be able and willing to pay for PrEP that was less than Can $\$ 100$. The second most commonly identified motivator was already knowing someone who uses the approach $(52.5 \%$, 74/141).

The most commonly identified barriers to using the border-crossing approach at baseline were concerns about the legality of the approach $(56.0 \%, 79 / 141)$, the safety of using online vendors $(38.3 \%, 54 / 141)$, and the security of personal health information $(36.9 \% ; 52 / 141$; Figure 2$)$. The findings for motivators and barriers were similar at follow-up, except that $40.9 \%$ (45/110) of participants identified a new barrier being that it had become easier to get generic PrEP in Canada instead. We added this response option for the follow-up questionnaire only because domestically manufactured generic PrEP became available and partially publicly subsidized in Ontario in late 2017, before follow-up data collection began. Although $44.5 \%$ (49/110) of follow-up participants reported that they would be less likely to use the border-crossing approach given these policy changes, $86.3 \%(95 / 110)$ were unaware of the new changes before beginning the follow-up survey. 
Figure 2. Reported barriers to using the border-crossing strategy. PrEP: pre-exposure prophylaxis.

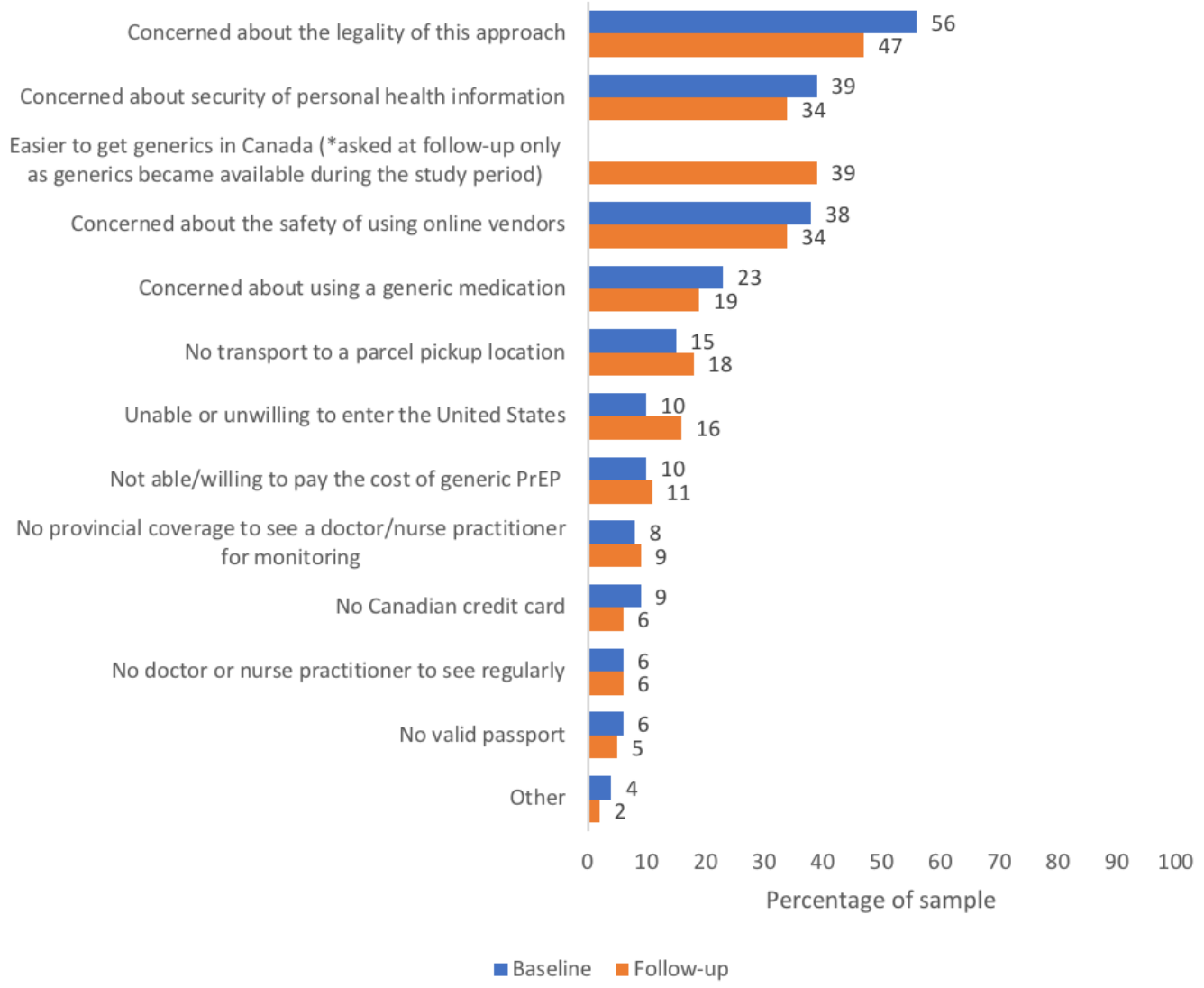

\section{Checking Response Quality}

We conducted a sensitivity analysis comparing the decile of respondents $(n=14)$ with the shortest survey completion times to the total sample. Response proportions for both groups were consistent across both the primary outcome and the demographic characteristics included in Table 1 (data not shown).

\section{Discussion}

\section{Principal Findings}

Understanding both who is considering online alternatives for PrEP access and why they are doing so is vital to understanding gaps in PrEP implementation. In our sample of mostly Toronto-based, black GBMSM, we found high interest in pursuing an innovative approach to obtaining PrEP medications, involving online ordering and cross-border retrieval, measuring $80.1 \%(113 / 141)$ at baseline and $79.1 \%(87 / 110)$ at follow-up. Participants identified both key motivators (eg, knowing someone who uses a border-crossing approach and high domestic costs) and barriers (eg, concerns about the legality of such an approach, security of personal health information, and the safety of online vendors) to pursuing this strategy. To our knowledge, this is the first study regarding this Web-based, border-crossing approach to obtain PrEP medications.

The proportion of black participants was surprisingly high at $79.0 \%(112 / 141)$, given that less than $5 \%$ of Ontario's men identify as black [17], raising the possibility of sampling bias. However, the direction of any such bias is unclear, and our primary purpose was to assess the intentions of those accessing the online resource rather than those of the GBMSM population as a whole. We suspect that the high number of black participants is a result of social networks circulating the online link to the study survey; $66.1 \%$ (74/112) of black participants reported that they had heard of the border-crossing strategy from friends vs only $22.9 \%(6 / 29)$ of nonblack participants. Given that North American black GBMSM have historically been both socioeconomically disadvantaged and harder to engage in HIV prevention research [18-21], our high number of black respondents may reflect an unmet need for alternative methods of PrEP access in this population, and the advantages of using Web-based approaches for reaching and studying the needs of marginalized populations.

\section{Comparison With Previous Work}

Online PrEP shopping has been a major alternative approach for accessing PrEP among GBMSM in other jurisdictions such as the United Kingdom and Australia. Online purchasing of inexpensive PrEP likely played a causal role in lowering the rates of HIV infection among GBMSM at sexual health clinics in the United Kingdom [22,23] and filled a critical access gap in the formal health care system, where the National Health Service has decided not to fund PrEP medication [24]. UK online information pages such as I want PrEP Now were precursors to the Web pages created by Canadian activists and community organizations (eg, The Davie Buyers Club and the GMSH's The PrEP You Want campaign) [25], and many of these pages refer users to the same pool of Web-based international generic medication suppliers. Similarly in Australia, online purchasing, often championed by community groups and websites, was the primary means of PrEP access 
before the eventual public listing of PrEP on the national drug benefit scheme in 2018 [26,27]. In British Columbia, limited data from 2017 suggest that 200 individuals accessed PrEP through The Davie Buyers Club over a 3-month period, though detailed information on the characteristics and experiences of these individuals is lacking [9]. Although there has been some concern over the quality of medications ordered online, both in our sample and in the literature [28,29], evidence from both the UK and Canadian contexts suggests that online PrEP distributors provide safe and effective generic medications [30,31]. However, given the complexity and inconvenience involved in border crossing to obtain PrEP, we contend that this strategy is not the optimal way to make this primary prevention strategy available in Canada, and PrEP needs to be more widely available to Canadians at risk.

Following in the mold of HIV cascades, hypothetical PrEP cascades have been proposed and used to identify bottlenecks at different stages of PrEP implementation [32-34]. For instance, our previous hypothetical PrEP cascade found that although $64.4 \%$ of Toronto GBMSM undergoing anonymous HIV testing were at objectively high HIV risk, $68.3 \%$ did not perceive themselves to be at elevated risk and $47.6 \%$ lacked access to a family doctor [7]. Our hypothetical cascade of border-crossing steps identified parallel bottlenecks in accessing health care providers and obtaining PrEP prescriptions. These data highlight the need for continued efforts to make PrEP providers and PrEP medication widely accessible, even in large urban centers such as Toronto.

Two positive developments in Ontario's PrEP access landscape have been the entry of generics into the Canadian PrEP market (August 2017) and the government's initiation of partial public subsidization (September 2017). As a result, PrEP costs have been reduced (the generic currently costs approximately Can $\$ 220$ per month) or largely covered (for Ontarians meeting the criteria for public drug benefits, sometimes involving copayment) [35]. As indicated by the $40.9 \%$ (45/110) of follow-up study participants who cited the availability of cheap generics in Canada as a deterrent to pursuing a border-crossing approach, this shift in cost has made conventional approaches to obtaining PrEP more viable for many potential users. However, despite the availability of reduced-cost generics in Ontario, our previous work demonstrated that PrEP could in some cases be obtained online for as little as Can $\$ 33$ per month [31], representing a cost savings of approximately $\$ 187$ per month over the generic TDF/FTC available in Ontario.

However, PrEP remains financially inaccessible for many potential users in Canada. This held true in our sample where $57.4 \%$ (81/141) participants identified a maximum monthly amount that they would be able and willing to pay for PrEP that was less than Can $\$ 100$. Although Can $\$ 33$ per month for online PrEP is within this range, the attrition we observed in our border-crossing cascade suggests that relying on online purchasing, even at this price, is not a viable public health strategy for improving PrEP accessibility. Given the recent findings of real-world reductions in HIV incidence of up to $100 \%$ in PrEP users, and PrEP's role in the substantial reductions in HIV incidence in settings such as San Francisco and New South Wales [36-39], Canada's inconsistent access to this major public health tool emphasizes the urgent need for truly universal coverage. This is particularly important given the failure of HIV incidence to decline among Canadian GBMSM in recent years [40].

\section{Limitations}

This study has several limitations that warrant consideration. First, because our study was an anonymous open online survey, it was not possible to exclude repeat participants, and some may have been motivated by the modest financial compensation. We attempted to minimize repeats by requiring participants to enter unique study codes that were assigned to each respondent's email address. We also checked for possible falsified responses by conducting a sensitivity analysis, which showed consistency between the demographic characteristics and primary outcome responses among the fastest decile of responders and the total sample. Second, hypothetical bias may have inflated the number of participants indicating likeliness to use this fairly time-intensive border-crossing approach [41]. We addressed this possibility in part by asking about the actual completion of cascade steps at 3-month follow-up. In addition, however, the relatively short time frame ( 3 months) between baseline and follow-up may still have been insufficient to capture participants' progress in using the border-crossing approach. These last two biases may in part explain why we found no participants who had completed every step of the border-crossing approach at follow-up. Furthermore, it is notable that although half of the respondents reportedly knew someone using the border-crossing approach, very few respondents actually did so themselves. This discrepancy raises the possibilities that respondents were underreporting their use of the procedure, that our study underrecruited individuals already successfully using this strategy, or that a limited number of border crossers were known to a large number of respondents. Finally, because we calculated HIRI-MSM scores for our participants by doubling the responses given for the past 3 months (rather than directly asking about the past 6 months), they may have deviated slightly from true scores. Moreover, HIRI-MSM scoring may be less relevant to the contemporary context as HIV risk through condomless sex can be reduced to zero with HIV treatment as prevention and/or PrEP. Regardless, our sample was likely still at high HIV risk because of its young age, high mean number of sex partners, frequent condomless receptive anal sex, and a $35 \%$ participation rate in chemsex.

\section{Conclusions}

PrEP is a promising tool for curbing high rates of HIV in GBMSM communities, but access remains highly variable in Canada. Our results suggest that despite the falling price of PrEP medications and some government subsidization, many potential PrEP users remain interested in alternative, cheaper methods of obtaining PrEP medications such as online shopping and border crossing. Effective PrEP implementation will require alternative strategies such as universal public coverage to ensure readily accessible PrEP medications for GBMSM living in Canada. 


\section{Acknowledgments}

The authors would like to acknowledge the survey respondents, the Gay Men's Sexual Health Alliance, Black CAP, and St. Michael's Hospital for their input and support.

This work was supported by a grant from the Canadian Institutes of Health Research (grant number HIM 145368). DHST is supported by a New Investigator Award from the Canadian Institutes of Health Research and the Ontario HIV Treatment Network. AS is the creator of the Davie Buyers Club resource and DG is a cocreator of The PrEP You Want resource.

\section{Conflicts of Interest}

In the past 3 years, DHST has received research grants from ViiV Healthcare and Gilead Sciences and has been a site principal investigator for clinical trials sponsored by GlaxoSmithKline.

\section{References}

1. Bourgeois AC, Edmunds M, Awan A, Jonah L, Varsaneux O, Siu W. Government of Canada. 2017. HIV in Canada-Supplementary Tables, 2016 URL: https:/www.canada.ca/en/public-health/services/reports-publications/ canada-communicable-disease-report-ccdr/monthly-issue/2017-43/ccdr-volume-43-12-december-7-2017/ hiv-2016-supplementary-tables.html[WebCite Cache ID 74ENfi3cu]

2. Grant RM, Lama JR, Anderson PL, McMahan V, Liu AY, Vargas L, iPrEx Study Team. Preexposure chemoprophylaxis for HIV prevention in men who have sex with men. N Engl J Med 2010 Dec 30;363(27):2587-2599 [FREE Full text] [doi: 10.1056/NEJMoa1011205] [Medline: 21091279]

3. Anderson PL, Glidden DV, Liu A, Buchbinder S, Lama JR, Guanira JV, iPrEx Study Team. Emtricitabine-tenofovir concentrations and pre-exposure prophylaxis efficacy in men who have sex with men. Sci Transl Med 2012 Sep 12;4(151):151ra125 [FREE Full text] [doi: 10.1126/scitranslmed.3004006] [Medline: 22972843]

4. Grant RM, Anderson PL, McMahan V, Liu A, Amico KR, Mehrotra M, iPrEx Study Team. Uptake of pre-exposure prophylaxis, sexual practices, and HIV incidence in men and transgender women who have sex with men: a cohort study. Lancet Infect Dis 2014 Sep;14(9):820-829 [FREE Full text] [doi: 10.1016/S1473-3099(14)70847-3] [Medline: 25065857]

5. Molina JM, Capitant C, Spire B, Pialoux G, Cotte L, Charreau I, ANRS IPERGAY Study Group. On-demand preexposure prophylaxis in men at high risk for HIV-1 infection. N Engl J Med 2015 Dec 3;373(23):2237-2246. [doi: 10.1056/NEJMoa1506273] [Medline: 26624850]

6. Wilton J, Kain T, Fowler S, Hart TA, Grennan T, Maxwell J, et al. Use of an HIV-risk screening tool to identify optimal candidates for PrEP scale-up among men who have sex with men in Toronto, Canada: disconnect between objective and subjective HIV risk. J Int AIDS Soc 2016;19(1):20777 [FREE Full text] [doi: 10.7448/IAS.19.1.20777] [Medline: 27265490]

7. Formulary Search. URL: https://www.formulary.health.gov.on.ca/formulary/[WebCite Cache ID 74ENpmKEE]

8. Immunodeficiency Clinic. 2018. Provincial/Territorial Coverage of ARV Drugs for HIV Prevention Across Canada:Post-exposure Prophylaxis (PEP) and Pre-exposure Prophylaxis (PrEP) URL: https://hivclinic.ca/wp-content/ uploads/2018/04/ARV-Coverage PEP-and-PrEP.pdf[WebCite Cache ID 74ENzf1xa]

9. Smith A. Davie Buyers club: history and current state of the generic PrEP importation pathway. In: Proceedings of the 13th Annual Gay Men's Health Summit. 2017 Presented at: Romancing the Package'13; November 2-4, 2017; Vancouver, Canada URL: https://d3n8a8pro7vhmx.cloudfront.net/vancitystudios/pages/19322/attachments/original/1534990785/ cbrc summit17 web-2 0.pdf?1534990785

10. Government of Canada: Justice Laws. 2018. Food and Drug Regulations (CRC, c 870) URL: http://laws.justice.gc.ca/eng/ regulations/c.r.c., c. 870/index.html[WebCite Cache ID 74EO9aD0t]

11. Davie Buyers Club. 2018. How to Access PrEP Without Insurance in Canada (for \$45 CAD Per Month) URL: https:/ /daviebuyersclub.wordpress.com/[WebCite Cache ID 74EOUMD7c]

12. The Sex You Want. 2016. The PrEP You Want: How to Order PrEP Online URL: http://thesexyouwant.ca/wp-content/ uploads/2016/06/The-PrEP-You-Want-how-to-order-PrEP-Online-final-updated-1.pdf[WebCite Cache ID 74EOed40B]

13. Rana J, Wilton J, Fowler S, Hart TA, Bayoumi AM, Tan DH. Trends in the awareness, acceptability, and usage of HIV pre-exposure prophylaxis among at-risk men who have sex with men in Toronto. Can J Public Health 2018 Dec;109(3):342-352 [FREE Full text] [doi: 10.17269/s41997-018-0064-3] [Medline: 29981088]

14. Wray R, Branka A, Bennett-AbuAyyash C, Tuck A. St. Michael's Hospital. 2013. We Ask Because We Care: The Tri-Hospital + TPH Health Equity Data Collection Research Project Report URL: http://www.stmichaelshospital.com/quality/ equity-data-collection-report.pdf[WebCite Cache ID 74EOigtzM]

15. Smith DK, Pals SL, Herbst JH, Shinde S, Carey JW. Development of a clinical screening index predictive of incident HIV infection among men who have sex with men in the United States. J Acquir Immune Defic Syndr 2012 Aug 1;60(4):421-427. [doi: 10.1097/QAI.0b013e318256b2f6] [Medline: 22487585]

16. Naing L, Winn T, Rusli BN. CiteSeerX. 2006. Practical Issues in Calculating the Sample Size for Prevalence Studies URL: http://citeseerx.ist.psu.edu/viewdoc/download?doi=10.1.1.504.2129\&rep=rep1\&type=pdf 
17. Statistics Canada. 2016. Census Profile, 2016 Census URL: https://www12.statcan.gc.ca/census-recensement/2016/dp-pd/ prof/index.cfm?Lang=E[WebCite Cache ID 74EOn33YS]

18. Millett GA, Peterson JL, Flores SA, Hart TA, Jeffries WL, Wilson PA, et al. Comparisons of disparities and risks of HIV infection in black and other men who have sex with men in Canada, UK, and USA: a meta-analysis. Lancet 2012 Jul 28;380(9839):341-348. [doi: 10.1016/S0140-6736(12)60899-X] [Medline: 22819656]

19. Eaton LA, Driffin DD, Bauermeister J, Smith H, Conway-Washington C. Minimal awareness and stalled uptake of pre-exposure prophylaxis (PrEP) among at risk, HIV-negative, black men who have sex with men. AIDS Patient Care STDS 2015 Aug;29(8):423-429 [FREE Full text] [doi: 10.1089/apc.2014.0303] [Medline: 26083143]

20. Smith DK, Toledo L, Smith DJ, Adams MA, Rothenberg R. Attitudes and program preferences of African-American urban young adults about pre-exposure prophylaxis (PrEP). AIDS Educ Prev 2012 Oct;24(5):408-421. [doi: 10.1521/aeap.2012.24.5.408] [Medline: 23016502]

21. Matthews DD, Herrick AL, Coulter RW, Friedman MR, Mills TC, Eaton LA, POWER Study Team. Running backwards: consequences of current HIV incidence rates for the next generation of black MSM in the United States. AIDS Behav 2016 Jan;20(1):7-16 [FREE Full text] [doi: 10.1007/s10461-015-1158-z] [Medline: 26267251]

22. Brown AE, Mohammed H, Ogaz D, Kirwan PD, Yung M, Nash SG, et al. Fall in new HIV diagnoses among men who have sex with men (MSM) at selected London sexual health clinics since early 2015: testing or treatment or pre-exposure prophylaxis (PrEP)? Euro Surveill 2017 Jun 22;22(25):pii: 30553 [FREE Full text] [doi:

10.2807/1560-7917.ES.2017.22.25.30553] [Medline: 28662762]

23. Aloysius I, Savage A, Zdravkov J, Korologou-Linden R, Hill A, Smith R, et al. InterPrEP. Internet-based pre-exposure prophylaxis with generic tenofovir DF/emtricitabine in London: an analysis of outcomes in 641 patients. J Virus Erad 2017 Oct 1;3(4):218-222 [FREE Full text] [doi: 10.1111/hiv.12528] [Medline: 29057086]

24. Kirby T. HIV pre-exposure prophylaxis: a tale of two countries. Lancet Infect Dis 2017 Dec;17(1):32-33. [doi: 10.1016/S1473-3099(16)30562-X] [Medline: 27998575]

25. I Want PrEP Now. URL: https://www.iwantprepnow.co.uk/[WebCite Cache ID 74EOwHIYa]

26. Holt M, Lea T, Schmidt H, Kolstee J, Ellard J, Murphy D, et al. Willingness to use and have sex with men taking HIV pre-exposure prophylaxis (PrEP): results of online surveys of Australian gay and bisexual men, 2011-2015. Sex Transm Infect 2017 Dec;93(6):438-444. [doi: 10.1136/sextrans-2016-052774] [Medline: 28108701]

27. Holt M, Lea T, Bear B, Halliday D, Ellard J, Murphy D, et al. Trends in attitudes to and the use of HIV pre-exposure prophylaxis by Australian gay and bisexual men, 2011-2017: implications for further implementation from a diffusion of innovations perspective. AIDS Behav 2019 Jul;23(7):1939-1950. [doi: 10.1007/s10461-018-2368-y] [Medline: 30539496]

28. Baert B, de Spiegeleer B. Quality analytics of internet pharmaceuticals. Anal Bioanal Chem 2010 Sep;398(1):125-136. [doi: 10.1007/s00216-010-3912-4] [Medline: 20582403]

29. Wang T, Hoag SW, Eng ML, Polli J, Pandit NS. Quality of antiretroviral and opportunistic infection medications dispensed from developing countries and internet pharmacies. J Clin Pharm Ther 2015 Feb;40(1):68-75. [doi: 10.1111/jcpt.12226] [Medline: 25381836]

30. Wang X, Nwokolo N, Korologou-Linden R, Hill A, Whitlock G, Day-Weber I, et al. InterPrEP: internet-based pre-exposure prophylaxis with generic tenofovir disoproxil fumarate/emtrictabine in London - analysis of pharmacokinetics, safety and outcomes. HIV Med 2018 Dec;19(1):1-6. [doi: 10.1111/hiv.12528] [Medline: 28657199]

31. Lott A, Naccarato M, Turton R, Tan DH. POPPEE: Purchasing Online Pre-Exposure Prophylaxis (PrEP) Pills to Evaluate Equivalence. In: Proceedings of the 26th Annual Canadian Conference on HIV/AIDS Research. 2017 Presented at: CAHR'17; April 6-9, 2017; Montreal, Quebec.

32. Liu A, Colfax G, Cohen S, Bacon O, Kolber M, Amico KR, et al. The Spectrum of Engagement in HIV Prevention: Proposal for a PrEP Cascade. In: Proceedings of the 7th International Conference on HIV Treatment and Prevention Adherence. 2012 Presented at: Adherence'12; June 3-5, 2012; London, UK.

33. Parsons JT, Rendina HJ, Lassiter JM, Whitfield TH, Starks TJ, Grov C. Uptake of HIV pre-exposure prophylaxis (PrEP) in a national cohort of gay and bisexual men in the United States. J Acquir Immune Defic Syndr 2017 Dec 1;74(3):285-292 [FREE Full text] [doi: 10.1097/QAI.0000000000001251] [Medline: 28187084]

34. Kelley CF, Kahle E, Siegler A, Sanchez T, del Rio C, Sullivan PS, et al. Applying a PrEP continuum of care for men who have sex with men in Atlanta, Georgia. Clin Infect Dis 2015 Nov 15;61(10):1590-1597 [FREE Full text] [doi: 10.1093/cid/civ664] [Medline: 26270691]

35. Ontario. 2018. Get Coverage for Prescription Drugs URL: https://www.ontario.ca/page/ get-coverage-prescription-drugs [WebCite Cache ID 74EQ6D7SU]

36. McCormack S, Dunn DT, Desai M, Dolling DI, Gafos M, Gilson R, et al. Pre-exposure prophylaxis to prevent the acquisition of HIV-1 infection (PROUD): effectiveness results from the pilot phase of a pragmatic open-label randomised trial. Lancet 2016 Jan 2;387(10013):53-60 [FREE Full text] [doi: 10.1016/S0140-6736(15)00056-2] [Medline: 26364263]

37. Volk JE, Marcus JL, Phengrasamy T, Blechinger D, Nguyen DP, Follansbee S, et al. No new HIV infections with increasing use of HIV preexposure prophylaxis in a clinical practice setting. Clin Infect Dis 2015 Nov 15;61(10):1601-1603 [FREE Full text] [doi: 10.1093/cid/civ778] [Medline: 26334052] 
38. San Francisco Department of Public Health. 2016. HIV Epidemiology: Annual Report 2016 URL: https://www.sfdph.org/ dph/files/reports/RptsHIVAIDS/Annual-Report-2016-20170831.pdf[WebCite Cache ID 74EQDuSgt]

39. Grulich AE, Guy R, Amin J, Jin F, Selvey C, Holden J, Expanded PrEP Implementation in Communities New South Wales (EPIC-NSW) research group. Population-level effectiveness of rapid, targeted, high-coverage roll-out of HIV pre-exposure prophylaxis in men who have sex with men: the EPIC-NSW prospective cohort study. Lancet HIV 2018 Dec;5(11):e629-e637. [doi: 10.1016/S2352-3018(18)30215-7] [Medline: $\underline{30343026}$ ]

40. The Ontario HIV Epidemiology and Surveillance Initiative. 2016. New HIV Diagnoses in Ontario: Preliminary Update, 2016 URL: http://www.ohesi.ca/documents/OHESI-New-HIV-Diagnoses-preliminary-updates.pdf]WebCite Cache ID 76cCFxayD]

41. List JA, Gallet CA. What experimental protocol influence disparities between actual and hypothetical stated values? Environ Resour Econ 2001;20(3):241-254. [doi: 10.1023/A:1012791822804]
Abbreviations
aOR: adjusted odds ratio
GBMSM: gay, bisexual, and other men who have sex with men
GMSH: Gay Men's Sexual Health Alliance
HIRI-MSM: High Incidence Risk Index for men who have sex with men
IQR: interquartile range
PrEP: pre-exposure prophylaxis
TDF/FTC: tenofovir disoproxil fumarate and emtricitabine

\author{
Edited by G Eysenbach; submitted 28.11.18; peer-reviewed by M Holt, T Starks; comments to author 10.01.19; revised version received \\ 07.03.19; accepted 16.04.19; published 22.07.19 \\ Please cite as: \\ Walmsley B, Gallant D, Naccarato M, Hull M, Smith A, Tan DHS \\ The PrEP You Want: A Web-Based Survey of Online Cross-Border Shopping for HIV Prophylaxis Medications \\ J Med Internet Res 2019;21(7):e12076 \\ URL: http://www.jmir.org/2019/7/e12076/ \\ doi: $10.2196 / 12076$ \\ PMID: $\underline{31333200}$
}

(CBen Walmsley, Dan Gallant, Mark Naccarato, Mark Hull, Alex Smith, Darrell Hoi-San Tan. Originally published in the Journal of Medical Internet Research (http://www.jmir.org), 22.07.2019. This is an open-access article distributed under the terms of the Creative Commons Attribution License (https://creativecommons.org/licenses/by/4.0/), which permits unrestricted use, distribution, and reproduction in any medium, provided the original work, first published in the Journal of Medical Internet Research, is properly cited. The complete bibliographic information, a link to the original publication on http://www.jmir.org/, as well as this copyright and license information must be included. 